\title{
IMPLEMENTASI TEKNIK FOLEY DAN VOICE OVER DALAM PEMBUATAN FILM DOKUMENTER WONDERFUL BATAM
}

\author{
Julio Tathohud Putera Kuba ${ }^{1}$, Happy Yugo Prasetiya ${ }^{2}$ \\ * Informatics Engineering, Batam State Polytechnic \\ ** Multimedia and Network Engineering, Batam State Polytechnic \\ tathojulio30@gmail.com $^{1}$, happy.yugo@gmail.com ${ }^{2}$
}

\begin{tabular}{l}
\hline Article Info \\
\hline Article history: \\
Received Jun $12^{\text {th }}, 2021$ \\
Revised Jun $20^{\text {th }}, 2021$ \\
Accepted Jul $26^{\text {th }}, 2021$ \\
\hline
\end{tabular}

\section{Keyword:}

Foley

Voice over

Villamil-Molina

Sound design

Film dokumenter

\begin{abstract}
Film dokumenter Wonderful Batam adalah video dokumenter yang menampilkan 3 destinasi wisata yang ada di kota Batam, yaitu wisata hiburan, wisata kuliner dan wisata religi. Para penikmat dan kreator film sering hanya mengedepankan elemen visual dalam pembuatan film. Padahal, di dalam sebuah film juga terdapat elemen audio yang juga berperan penting dalam mendukung menggambarkan emosi dan pesan yang ingin di sampaikan dalam film. Tujuan penelitian ini adalah untuk mengimplementasikan teknik foley dan voice over pada pembuatan audio dalam film dokumenter Wonderful Batam, hal ini dilakukan untuk memperjelas informasi dan suasana yang terjadi di dalam video serta memperbaiki audio pada film dokumenter Wonderful Batam, dimana berfokus untuk memaksimalkan teknik foley dan voice over dalam pembuatannya. Metode pembuatan film dokumenter Wonderful Batam menggunakan metode Villamil-Molina yang terdiri dari 5 tahapan development, prep roduction, production, post production, dan delivery dimana teknik foley dan voice over dilakukan pada tahap post production. Film dokumenter Wonderfull Batam kemudian dilakukan pengujian alfa kepada ahli media dan beta kepada 30 responden. Diharapkan penelitian ini dapat memperkenalkan teknik foley dan voice over kepada para pembaca yang sedang mempelajari topik pembuatan film
\end{abstract}

\section{PENDAHULUAN}

Film merupakan sebuah karya perpaduan antara dua elemen yang saling mendukung yaitu elemen visual dan elemen audio. Sebuah karya film dapat dikatakan berhasil apabila semua faktor yang mendukung di dalam film tersebut saling mendukung sehingga menghasilkan sebuah karya film yang indah [1]. Film dokumenter adalah film yang menceritakan sebuah kejadian nyata namun dalam pembuatannya tetap memasukkan ide dan pemikiran kreator nya. Selain untuk hiburan salah satu fungsi film adalah untuk pendidikan, karena di dalam film banyak terkandung informasi.

Penggunaan suara di dalam film terus mengalami kemajuan, suara di dalam film dapat di desain dan diatur untuk mendapatkan hasil suara yang maksimal dan sesuai dengan kebutuhan film, fungsi suara di dalam film ini diantaranya untuk mendukung alur cerita dengan cara membangun mood menggunakan dialog, musik, dan sound effect [2]. Beberapa suara diantaranya menjadi satu dengan gambar (diegetic), dan beberapa lagi benar-benar diluar gambar seperti music dan voice over (non diegetic).

Para penikmat dan kreator film sering hanya mengedepankan elemen visual dalam pembuatan film, padahal di dalam film juga terdapat elemen audio yang juga berperan penting dalam mendukung menggambarkan emosi dan pesan yang ingin disampaikan dalam film tersebut [3]. Berdasarkan hal tersebut mendorong perlunya penelitian ilmiah untuk mengimplementasikan dan mengevaluasi peran audio di dalam sebuah film dokumenter, penulis sebagai sound designer akan menerapkan teknik foley dan voice over ke dalam beberapa scene pada film dokumenter Wonderful Batam, ini sekaligus bertujuan agar mengetahui bagaimana penerapan teknik foley dan voice over dalam film dokumenter Wonderfull Batam, setelah foley dan voice over sudah diimplementasikan kedalam film dokumenter maka akan diketahui apakah ada keefektifan dalam penyampaian film dokumenter yang telah dibuat. Film dokumenter Wonderful Batam adalah film dokumenter 
yang menginformasikan keindahan pariwisata kota Batam mulai dari wisata hiburan, kuliner dan juga wisata religi.

Dimana peran teknik foley digunakan untuk mendukung suasana adegan yang sedang terjadi pada film serta memberikan kejelasan terhadap adegan yang sedang terjadi di dalam film, karena ada begitu banyak suara yang terdengar pada saat adegan tertentu di dalam film sehingga untuk membuat suara yang yang menjelaskan suatu adegan di dalam film secara alami maka dibutuhkan efek suara foley pada adegan film [1] dan teknik voice over berguna untuk menyediakan informasi tertentu dan sering menguraikan pesan yang ditujukan kepada audiens agar dapat menangkap informasi secara gamblang, dan voice over talent tidak tampak di dalam film [4],sehingga elemen audio yang dibuat diharap dapat mendukung elemen visual yang sudah ada menjadi suatu kesatuan film yang dapat dinikmati.

\section{METODE PENELITIAN}

\subsection{Metode Penyelesaian Masalah}

Metode pengembangan yang akan digunakan adalah metode pengembangan Villamil-Molina, dimana tahapan ini terdiri dari 5 tahapan [5] yaitu development, preproduction, production, postproduction, delivery.

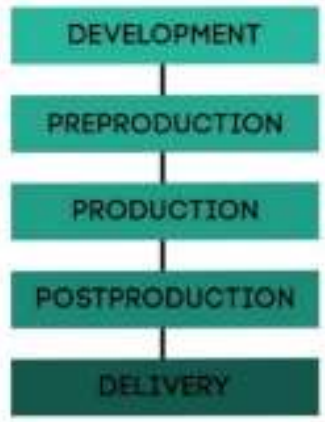

Gambar 1. Metode VIllamil-Molina

Dalam bagian metodologi hanya akan menjelaskan 2 tahapan (Development \& PreProduction) dari 5 tahapan yang ada pada metode Villamil-Molina, dan tahap yang lainnya akan dibahas di bagian Hasil dan Pembahasan.

1. Development

Pada tahap ini dilakukan untuk menentukan ide konsep serta daftar keperluan untuk proses produksi film yang akan dibuat, Adapun ide yang didapat adalah mengimplementasikan teknik foley dan voice over di dalam sebuah film dokumenter.

Tabael 1. Development Wonderful Batam

\begin{tabular}{|l|l|}
\hline \multicolumn{2}{|c|}{ Development } \\
\hline Ide & Implementasi teknik foley dan voice overdalam sebuah film dokumenter \\
\hline Konsep & $\begin{array}{l}\text { Film dokumenter mengenai kota batam yang berfokus pada 3 destinasi yaitu hiburan, kuliner, dan religi dan } \\
\text { menggunakan foley sebagai penjelas suasana yang terjadi pada video, dan voice over untuk memperjelas informasi } \\
\text { yang ada pada video. }\end{array}$ \\
\hline Lokasi & Destinasi wisata hiburan, kuliner, dan religi yang ada di kota batam. Studio yang berlokasi di batu aji. \\
\hline Keperluan & Kamera, stabilizer, laptop, lighting, dan perlengkapan lainnya (jika dibutuhkan) \\
\hline
\end{tabular}

2. Preproduction

Tahapan kedua dari Villamil-Molina ini berguna untuk mempersiapkan dan melakukan kegiatan sebelum dimulainya proses produksi. Seperti membuat synopsis, membuat storyboard. Untuk bagian foley dan voice over dipersiapkan naskah, perancangan bahan untuk membuat suara foley.

a. Sinopsis

Sinopsis merupakan ringkasan dari semua isi cerita yang akan terjadi di dalam film, berikut sinopsis film dokumenter Wonderful Batam.

Tabel 2. Sinopsis 
sebuah botol tak sengaja diinjak oleh seseorang, ketika melihat isi kotak ternyata kotak berisi kertas yang bertuliskan wonderfull batam, wonderfull batam bercerita tentang keindahan batam dari segi wisata hiburan, wisata kuliner dan wisata religi. Wisata hiburan terdiri dari perjalanan ke Alun-alun Engku Putri - Pantai Nongsa - Pantai Vio-vio - Kebun Raya Batam - Ocarina - Golden Prawn, wisata kuliner bercerita mengenai perjalanan ke Piayu Laut - Tiban Centre - Wtb -Nagoya Hill Food Street, wisata religi berisi perjalanan ke tempat tempat ibadah seperti Masjid Raya - Jabal Arafah - Masjid Sultan Mahmud Riayat Syah - Gereja St Petrus - Vihara Maiterya Pura Agung Amerta Bhuana - Mesjid \& Gereja di Pelita.

b. Naskah

Naskah akan dibuat pada tahap pre production kemudian akan dibacakan oleh voice over talent ketika film yang dibuat selesai pada proses post production nanti. Berikut gambar potongan naskah film dokumenter Wonderfull Batam.

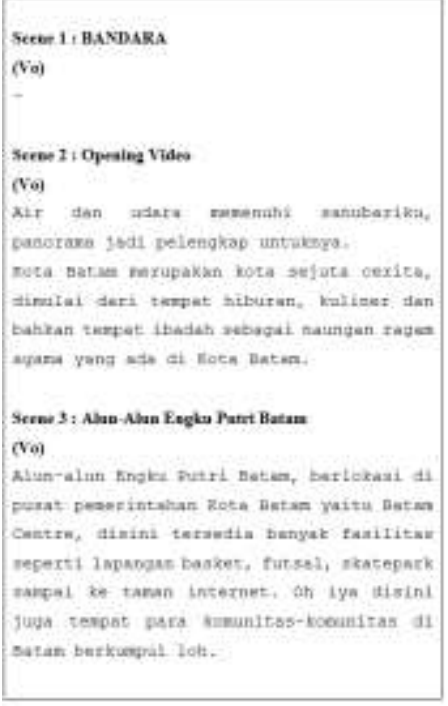

Gambar 2. Naskah Voice over

c. Perancangan Teknik Foley

Dalam tahap perancangan foley ini penulis mengumpulkan bahan/data sesuai dengan kebutuhan yang akan dilakukan. Berikut ini adalah pengelompokkan suara-suara apa saja yang akan dibuat nanti beserta bahan-bahannya.

Tabel 3. Perancangan Foley

\begin{tabular}{|l|l|l|}
\hline No. & Suara yang dihasilkan & Alat dan Bahan \\
\hline 1. & Angin & Ban dalam \\
\hline 2. & Langkah kaki & Kaki,Karpet \\
\hline 3. & Botol Diinjak & Botol \\
\hline 4. & Air mengalir & Botol berisi air, baskom \\
\hline 5. & Bendera & Kain \\
\hline 6. & Makan & Sendok, Piring \\
\hline 7. & Pesawat & Bor Listrik,Triplek \\
\hline 8. & Ombak & Baskom berisi air \\
\hline 9. & Ambience & Keramaian \\
\hline 10. & Lonceng sepeda & Sepeda \\
\hline 11. & Suara rantai sepeda & Ranatai sepeda \\
\hline 12. & Lonceng & Besi \\
\hline 13. & Kepakan sayap Burung & kain \\
\hline 14. & Menyiapkan makanan & Gelas,sendok \\
\hline 15. & Memasak & Teplon, kompor, air \\
\hline
\end{tabular}

d. Pemilihan Kru Produksi

Dalam metode Villamil-Molina, pemilihan kru produksi yang baik dapat membantu berjalannya proses produksi secara cepat dan tepat. Di dalam keterbatasan SDM dalam melakukan penelitian ini, maka tugas dari setiap kru akan dirangkap oleh perorangan.

Tabel 4. Kru Produksi

\begin{tabular}{|c|c|}
\hline Nama & Tanggung Jawab \\
\hline Julio Tatho & Sutradara, Sound Desigenr \\
\hline
\end{tabular}




\begin{tabular}{|c|c|}
\hline Suseno Adi Pamungkas & Sutradara, Videographer \\
\hline Miko Hutabarat & Videographer \\
\hline Asna Diana & Voice over Talent \\
\hline Dira & Actor \\
\hline
\end{tabular}

\subsection{Analisis \& Pengujian}

a. Analisis

Analisis yang digunakan menggunakan metode kuantitatif yang bertujuan untuk mengetahui pengaruh teknik foley dalam memperjelas suasana yang terjadi di dalam film dokumenter serta pengaruh teknik voice over di dalam memperjelas isi video. Responden akan diminta untuk menonton Video Wonderfull Batam. Aspek yang diukur dijabarkan menjadi indikator variabel, kemudian indikator tersebut dijadikan sebagai item-item yang berupa pertanyaan atau pernyataan yang akan diberikan kepada responden.

Berikut adalah aspek dan indikator yang akan diukur dan digunakan dalam analisis keefektifan penggunaan foley [6] dan indikator voice over [7] dalam film Wonderfull Batam :

Tabel 5. Indikator Analisis

\begin{tabular}{|c|l|}
\hline Aspek & \multicolumn{1}{|c|}{ Indikator } \\
\hline \multirow{2}{*}{ Suara Foley } & 1. Suara yang dihasilkan dapat mengganti suara aslinya \\
\cline { 2 - 2 } & 2. Suara yang dihasilkan mendukung suasana dalam film \\
\cline { 2 - 2 } & 3. Penempatan suara yang dihasilkan sudah tepat di dalam film \\
\hline \multicolumn{2}{|c|}{} \\
\hline \multirow{3}{*}{ Suara Voice over } & 1. Suara Voice over Terdengar Jelas \\
\cline { 2 - 2 } & 2. Istilah yang digunakan bersifat umum \\
\cline { 2 - 2 } & 3. Penggunaan kata-kata mudah dipahami \\
\hline
\end{tabular}

b. Pengujian

Pengujian akan dilakukan di tahap post production, metode penelitian yang digunakan untuk analisis adalah metode kuantitatif, pengujian akan dilakukan kepada 3 ahli media (Alpha Test) yang bertujuan untuk mengetahui apakah audio foley dan voice over yang diimplementasikan kedalam film dokumenter ini layak untuk diteruskan ke penonton. Untuk memperoleh data pengujian maka diperlukan suatu alat atau instrumen berupa kuesioner. Penilaian ahli akan diukur dalam perhitungan jarak interval untuk mengetahui hasil dari kuesioner [8].

\section{Jarak Interval $(i)=\underline{\text { Skor Tertinggi }- \text { Skor Terendah }}$ Jumlah Kelas Interval}

Berdasarkan perhitungan jarak interval diatas, berikut adalah kriteria dari penilaian ahli media

Tabel 6. Jarak Interval

\begin{tabular}{|c|c|}
\hline Rata-Rata & Kriteria \\
\hline $4,3-5,0$ & Sangat Setuju \\
\hline $3,5-4,2$ & Setuju \\
\hline $2,7-3,4$ & Cukup Setuju \\
\hline $1,9-2,6$ & Tidak Setuju \\
\hline $1,0-1,8$ & Sangat Tidak Setuju \\
\hline
\end{tabular}

Setelah penilaian para ahli terhadap implementasi foley dan voice over dalam film dokumenter ini sudah didapat dan mencapai nilai rata-rata"setuju", maka produk film dokumenter ini sudah layak untuk dilanjutkan ke tahap beta testing yaitu kuesioner yang ditujukan ke responden. Dalam penelitian ini, responden merupakan warga batam yang berada di batam kurang dari 1 tahun dan tidak memiliki riwayat gangguan pendengaran. Penulis menggunakan Metode skala likert untuk mengukur suatu perilaku individu dan juga digunakan untuk mengukur sikap, pendapat serta persepsi dari responden baik secara perorangan maupun kelompok [9]. Untuk perhitungan skor penulis menggunakan metode ini pada proses pembuatan kuesioner, terdapat bobot dan persentase nilai.

Tabel 7. Bobot Kuesioner

\begin{tabular}{|c|c|c|}
\hline No. & Pertanyaan & Bobot \\
\hline 1. & Sangat Setuju (SS) & 5 \\
\hline 2. & Setuju (S) & 4 \\
\hline 3. & Ragu-ragu (R) & 3 \\
\hline 4. & Tidak Setuju (TS) & 2 \\
\hline 5. & Sangat Tidak Setuju (STS) & 1 \\
\hline
\end{tabular}


Setelah data penilaian kuesioner didapatkan maka setelah itu menghitung total skor dengan rumus :

\section{Total Skor $=$ Jumlah Responden $\mathbf{x}$ Bobot}

Setelah total skor didapatkan, maka dilanjutkan dengan mencari skor maksimum dengan rumus :

\section{Skor Maksimum = Jumlah Responden X Bobot Tertinggi}

Skor maksimum yang didapat akan menentukan index dalam persenan dengan rumus :

$$
\text { Index }(\%)=(\text { Total skor / Skor Maksimum) X } 100
$$

Hasil dari perhitungan index (\%) akan merujuk dengan interval yang telah ditetapkan dalam skala likert.

Tabel 8. Interval Persentase Kuesioner

\begin{tabular}{|c|c|}
\hline Index (\%) & Hasil \\
\hline $80 \%-100 \%$ & Sangat Setuju \\
\hline $60 \%-79,99 \%$ & Setuju \\
\hline $40 \%-59,99 \%$ & Ragu-Ragu \\
\hline $20 \%-39,99 \%$ & Tidak Setuju \\
\hline $0 \%-19,99 \%$ & Sangat Tidak Setuju \\
\hline
\end{tabular}

\section{HASIL DAN PEMBAHASAN}

3. Production

Pada proses produksi ini semua perancangan yang dilakukan pada tahap sebelumnya akan di eksekusi dimulai dari take video kemudian dilanjutkan take audio. Berikut akan dijelaskan proses take audio yang berhubungan dengan penelitian ini.

a. Implementasi Teknik Foley

Teknik foley merupakan teknik yang digunakan untuk menghasilkan suara menggunakan bahan-bahan yang ada di sekitar, penonton film akan terpengaruh oleh suara foley sehingga suara yang dihasilkan dapat meningkatkan aliran naratif dalam film, seniman foley belajar dari pengalaman dan tahu apa yang harus mereka lakukan untuk merepresentasikan suara yang akan dibuat, tetapi mereka hampir tidak tahu suara yang mereka hasilkan bekerja dalam konteks tertentu [10] . Tidak ada batasan dalam menghasilkan audio dengan menggunakan teknik foley, setiap artis foley tampil berbeda, masing-masing memiliki gaya tersendiri, berkembang seiring waktu dan pengalaman. Cara terbaik untuk menyempurnakan teknik foley adalah dengan terus melakukannya [11]. Suara foley akan yang dibuat dalam menambah kejelasan suara dalam film dokumenter Wonderful Batam menggunakan bahan-bahan yang telah dikumpulkan pada proses pre production.

- Menonton Picture Locked

Sebelum melakukan recording suara foley sound designer harus menonton picture locked, picture locked adalah film yang sudah jadi namun belum memiliki suara, ini bertujuan untuk memberikan bayangan bagaimana suara foley akan dibuat dengan menggunakan bahan-bahan yang telah disediakan, dan pada scene mana saja yang akan diberikan suara foley.

- $\quad$ Recording Foley

Setelah menonton picture locked proses recording foley dilakukan menggunakan mic condenser Behringer sambil melihat monitor untuk mencocokan setiap suara yang akan dibuat dengan gerakan yang sedang terjadi di dalam film, recording dan editing audio digunakan menggunakan aplikasi adobe audition. Kemudian audio yang telah jadi akan digunakan di proses post production untuk di mixing dan dimasukkan kedalam film dokumenter menggunakan adobe premiere. 
b. Implementasi Voice over

Voice over talent akan membacakan naskah yang telah dibuat pada tahap pre production sebelumnya.

- Membaca Script

Sebelum melakukan recording, naskah akan dibaca terlebih dahulu agar voice over talent dapat memahami maksud dan makna yang akan disampaikan dari naskah yang telah dibuat tersebut.

- $\quad$ Recording Voice over

Pada proses recording ini dilakukan secara langsung menggunakan mic condenser Behringer yang dilakukan bersamaan dengan menonton film, bertujuan untuk menyesuaikan durasi voice over dengan scene yang akan diberikan voice over. Kemudian audio hasil recording voice over akan diedit menggunakan adobe audition setelah itu akan digunakan pada proses mixing dan dimasukkan kedalam film dokumenter menggunakan adobe premiere.

\section{PostProduction}

Pada tahapan ini data dari kegiatan produksi dikumpulkan dan dipilih sebelum masuk ke proses editing. Pada tahap ini suara foley dan voice over yang telah di recording dan di edit akan di sinkronisasi ke dalam video dan diletakkan di dalam scene-scene yang membutuhkan foley dan voice over. Dan pada setelah video dan audio sudah di mastering pada tahap ini juga akan dilakukan pengujian kepada 3 ahli media dan 30 responden untuk diberikan kuesioner mengenai implementasi teknik foley dan voice over di dalam film dokumenter Wonderfull Batam.

a. Sinkronisasi Foley dan Voice over

- Sinkronisasi audio foley dengan video

Tahapan ini semua audio foley yang sudah jadi akan dimasukkan dan disusun kedalam scene-scene yang membutuhkan suara foley menggunakan adobe premiere.

- Sinkronisasi audio voice over dengan video

Pada tahapan ini audio voice over yang sudah jadi akan dimasukkan dan disesuaikan dengan scene video yang membutuhkan voice over.

b. Pengujian

1. Alpha Testing Ahli Media

Pengujian kepada ahli media ini bertujuan untuk menguji kelayakan film dokumenter yang telah diimplementasikan foley dan voice over apakah nantinya layak untuk di publikasikan dan di tonton oleh penonton. Pengujian dilakukan terhadap 3 orang ahli media, Berikut hasil pegujian pada tabel 9.

Tabel 9. Hasil Alpha Testing Ahli Media

\begin{tabular}{|c|c|c|c|c|c|c|}
\hline \multirow[b]{2}{*}{ No. } & \multirow[b]{2}{*}{ Pertanyaan } & \multicolumn{3}{|c|}{ Penilai } & \multirow{2}{*}{$\begin{array}{c}\text { Jumlah } \\
\text { Skor }\end{array}$} & \multirow{2}{*}{ Rata-rata } \\
\hline & & A1 & $\mathbf{A 2}$ & A3 & & \\
\hline \multicolumn{7}{|c|}{$\begin{array}{rr}\text { Audio Foley } \\
\end{array}$} \\
\hline 1. & $\begin{array}{l}\text { Suara pesawat yang dibuat dengan teknik } \\
\text { foley pada menit 00:02 sudah sesuai } \\
\text { dengan suara aslinya }\end{array}$ & 5 & 4 & 4 & 13 & 4.3 \\
\hline 2. & $\begin{array}{l}\text { Suara langkah kaki yang dibuat dengan } \\
\text { teknik foley pada menit 00:16 sudah } \\
\text { sesuai dengan suara aslinya }\end{array}$ & 3 & 4 & 5 & 12 & 4 \\
\hline 3. & $\begin{array}{l}\text { Suara menginjak botol yang dibuat } \\
\text { dengan teknik foley pada menit 00:19 } \\
\text { sudah sesuai dengan suara aslinya }\end{array}$ & 3 & 4 & 5 & 12 & 4 \\
\hline
\end{tabular}




\begin{tabular}{|c|c|c|c|c|c|c|}
\hline 4. & $\begin{array}{l}\text { Suara ombak yang dibuat dengan teknik } \\
\text { foley pada menit 01:04 sudah sesuai } \\
\text { dengan suara aslinya }\end{array}$ & 5 & 4 & 5 & 14 & 4.6 \\
\hline 5. & $\begin{array}{l}\text { Suara angin yang dibuat dengan teknik } \\
\text { foley pada menit 01:25 sudah sesuai } \\
\text { dengan suara aslinya }\end{array}$ & 4 & 4 & 4 & 12 & 4 \\
\hline 6. & $\begin{array}{l}\text { Suara sepeda yang dibuat dengan teknik } \\
\text { foley pada menit 01:39 sudah sesuai } \\
\text { dengan suara aslinya }\end{array}$ & 5 & 5 & 4 & 14 & 4.6 \\
\hline 7 & $\begin{array}{l}\text { Suara bel sepeda yang dibuat dengan } \\
\text { teknik foley pada menit } 01: 42 \text { sudah } \\
\text { sesuai dengan suara aslinya }\end{array}$ & 4 & 5 & 5 & 14 & 4.6 \\
\hline .8 & $\begin{array}{l}\text { Suara makan diatas piring yang dibuat } \\
\text { dengan teknik foley pada menit } 02: 10 \\
\text { sudah sesuai dengan suara aslinya }\end{array}$ & 4 & 4 & 4 & 12 & 4 \\
\hline 9. & $\begin{array}{l}\text { Suara Menggoreng yang dibuat dengan } \\
\text { teknik foley pada menit 02:26 sudah } \\
\text { sesuai dengan suara aslinya }\end{array}$ & 3 & 4 & 5 & 12 & 4 \\
\hline 10. & $\begin{array}{l}\text { Suara mengaduk telur yang dibuat dengan } \\
\text { teknik foley pada menit } 02: 28 \text { sudah } \\
\text { sesuai dengan suara aslinya }\end{array}$ & 3 & 5 & 4 & 12 & 4 \\
\hline 11. & $\begin{array}{l}\text { Suara membuka pintu yang dibuat dengan } \\
\text { teknik foley pada menit 03:04 sudah } \\
\text { sesuai dengan suara aslinya }\end{array}$ & 5 & 4 & 5 & 14 & 4.6 \\
\hline 12. & $\begin{array}{l}\text { Suara air mengalir yang dibuat dengan } \\
\text { teknik foley pada menit 03:22 sudah } \\
\text { sesuai dengan suara aslinya }\end{array}$ & 5 & 4 & 5 & 14 & 4.6 \\
\hline 13. & $\begin{array}{l}\text { Penempatan foley pada setiap scene } \\
\text { tempat wisata sudah tepat }\end{array}$ & 4 & 4 & 4 & 12 & 4 \\
\hline 14. & $\begin{array}{l}\text { Penggunaan teknik foley di dalam scene } \\
\text { bandara mendukung suasana adegan yang } \\
\text { terjadi di dalam film }\end{array}$ & 5 & 5 & 4 & 14 & 4.6 \\
\hline 15. & $\begin{array}{l}\text { Penggunaan teknik foley di dalam scene } \\
\text { wisata hiburan mendukung suasana } \\
\text { adegan yang sedang terjadi di dalam film }\end{array}$ & 4 & 5 & 5 & 14 & 4.6 \\
\hline 16. & $\begin{array}{l}\text { Penggunaan teknik foley di dalam scene } \\
\text { wisata kuliner mendukung suasana adegan } \\
\text { yang sedang terjadi di dalam film }\end{array}$ & 4 & 5 & 5 & 14 & 4.6 \\
\hline 17. & $\begin{array}{l}\text { Penggunaan teknik foley di dalam scene } \\
\text { wisata religi mendukung suasana adegan } \\
\text { yang sedang terjadi di dalam film }\end{array}$ & 4 & 4 & 5 & 13 & 4.3 \\
\hline & Audi & oice & & & & \\
\hline 18. & Suara voice over terdengar jelas & 4 & 5 & 5 & 14 & 4.6 \\
\hline 19. & $\begin{array}{l}\text { Pemilihan kata voice over mudah } \\
\text { dipahami }\end{array}$ & 3 & 4 & 5 & 12 & 4 \\
\hline 20. & $\begin{array}{l}\text { Kesesuian voice over dengan adegan yang } \\
\text { berlangsung }\end{array}$ & 4 & 4 & 5 & 13 & 4.3 \\
\hline 21. & $\begin{array}{l}\text { Suara voice over menambah penyampaian } \\
\text { informasi mengenai pariwisata kota batam }\end{array}$ & 4 & 4 & 5 & 13 & 4.3 \\
\hline 22. & $\begin{array}{l}\text { Suara voice over pada film dokumenter } \\
\text { Wonderful Batam membantu anda lebih } \\
\text { fokus ketika menonton }\end{array}$ & 4 & 5 & 4 & 13 & 4.3 \\
\hline 23. & $\begin{array}{l}\text { Suara voice over pada film dokumenter } \\
\text { membuat film dokumenter lebih } \\
\text { berkualitas }\end{array}$ & 3 & 4 & 4 & 11 & 3.6 \\
\hline \multicolumn{2}{|c|}{ Jumlah } & 92 & 100 & 106 & & 98.5 \\
\hline \multicolumn{2}{|c|}{ Rata-rata } & 4 & 4.3 & 4.6 & & 4.4 \\
\hline \multicolumn{2}{|c|}{ Keterangan } & $\mathrm{S}$ & SS & SS & & SS \\
\hline
\end{tabular}

Setelah mengetahui hasil skor rata-rata dari para ahli media didapatkan rata-rata 4.4 yang masuk kedalam kategori (SS) sangat setuju. Maka, dapat disimpulkan bahwa film dokumenter yang diimplementasikan foley dan voice over sudah memenuhi kelayakan untuk dipublikasikan.

\section{Beta Testing Responden}

Pengujian ini merupakan pengujian terakhir sebelum video di delivery ke dalam social media instagram dan youtube. Pengujian akan dilakukan kepada 30 Responden warga batam dengan karateristik berikut :

- $\quad$ Umur (18-29) 
- Tinggal di batam kurang dari 1 tahun

- Tidak memiliki gangguan pendengaran

Menurut Roscoe yang dikutip oleh Hendry, ukuran sampel yang lebih dari 30 dan kurang dari 500 adalah tepat untuk suatu penelitian [12]. Responden akan menonton produk tugas akhir berupa Film dokumenter Wonderful Batam, yang telah diimplementasikan teknik foley dan voice over, dan kemudian akan dilanjutkan dengan pengisian kuesioner. Selain berdasarakan kriteria yang telah disarankan oleh para ahli ahli diatas, responden yang dipilih adalah responden yang memiliki pengalaman mendengarkan suara secara kritis, seperti orang yang mendengarkan musik hampir setiap hari sehingga memiliki kepekaan nada yang lebih baik dari responden yang lain [13]

Tabel 10. Hasil Beta Testing Responden

\begin{tabular}{|c|c|c|c|c|c|c|}
\hline \multirow{2}{*}{ No. } & \multirow{2}{*}{ Pertanyaan } & \multicolumn{5}{|c|}{ Jawaban } \\
\hline & & STS & TS & $\mathbf{R}$ & $\mathbf{S}$ & SS \\
\hline \multicolumn{7}{|c|}{ Audio Foley } \\
\hline 1. & $\begin{array}{l}\text { Suara pesawat yang dibuat dengan teknik foley } \\
\text { pada menit 00:02 terdengar seperti suara } \\
\text { aslinya }\end{array}$ & & & 1 & 12 & 17 \\
\hline 2. & $\begin{array}{l}\text { Suara langkah kaki yang dibuat dengan teknik } \\
\text { foley pada menit 00:16 terdengar seperti suara } \\
\text { aslinya }\end{array}$ & & & 2 & 13 & 15 \\
\hline 3. & $\begin{array}{l}\text { Suara menginjak botol yang dibuat dengan } \\
\text { teknik foley pada menit 00:19 terdengar seperti } \\
\text { suara aslinya }\end{array}$ & & & & 8 & 22 \\
\hline 4. & $\begin{array}{l}\text { Suara kepakan sayap burung yang dibuat } \\
\text { dengan teknik foley pada menit 00:55 terdengar } \\
\text { seperti suara aslinya }\end{array}$ & & & 5 & 6 & 19 \\
\hline 5. & $\begin{array}{l}\text { Suara ombak yang dibuat dengan teknik foley } \\
\text { pada menit 01:04 terdengar seperti suara } \\
\text { aslinya }\end{array}$ & & & & 17 & 13 \\
\hline 6. & $\begin{array}{l}\text { Suara angin yang dibuat dengan teknik foley } \\
\text { pada menit 01:25 terdengar seperti suara } \\
\text { aslinya }\end{array}$ & & 1 & 6 & 16 & 7 \\
\hline 7. & $\begin{array}{l}\text { Suara kayuhan sepeda yang dibuat dengan } \\
\text { teknik foley pada menit 01:39 terdengar seperti } \\
\text { suara aslinya }\end{array}$ & & & 6 & 15 & 9 \\
\hline 8. & $\begin{array}{l}\text { Suara bel sepeda yang dibuat dengan teknik } \\
\text { foley pada menit 01:42 terdengar seperti suara } \\
\text { aslinya }\end{array}$ & & & 1 & 9 & 20 \\
\hline 9. & $\begin{array}{l}\text { Suara aktivitas makan yang dibuat dengan } \\
\text { teknik foley pada menit } 02: 10 \text { terdengar seperti } \\
\text { suara aslinya }\end{array}$ & & & 8 & 15 & 7 \\
\hline 10. & $\begin{array}{l}\text { Suara menggoreng makanan yang dibuat } \\
\text { dengan teknik foley pada menit 02:26 terdengar } \\
\text { seperti suara aslinya }\end{array}$ & & & 3 & 14 & 13 \\
\hline 11. & $\begin{array}{l}\text { Suara mengocok telur yang dibuat dengan } \\
\text { teknik foley pada menit } 02: 28 \text { terdengar seperti } \\
\text { suara aslinya }\end{array}$ & & & 2 & 14 & 14 \\
\hline 12. & $\begin{array}{l}\text { Suara pintu yang dibuat dengan teknik foley } \\
\text { pada menit 03:04 terdengar seperti suara } \\
\text { aslinya }\end{array}$ & & & 1 & 13 & 16 \\
\hline 13. & $\begin{array}{l}\text { Suara air mengalir yang dibuat dengan teknik } \\
\text { foley pada menit 03:22 terdengar seperti suara } \\
\text { aslinya }\end{array}$ & & & 2 & 13 & 15 \\
\hline 14. & $\begin{array}{l}\text { Penggunaan audio foley pada video membuat } \\
\text { anda ikut merasakan suasana yang terjadi } \\
\text { dalam film dokumenter }\end{array}$ & & & 2 & 10 & 18 \\
\hline 15. & $\begin{array}{l}\text { Penggunaan audio foley pada video membantu } \\
\text { memperjelas keadaan yang terjadi di film } \\
\text { dokumenter }\end{array}$ & & & & 12 & 18 \\
\hline 16. & $\begin{array}{l}\text { Penggunaan audio foley pada video membuat } \\
\text { perhatian anda lebih terfokus dalam menonton } \\
\text { film dokumenter }\end{array}$ & & & 2 & 12 & 16 \\
\hline \multicolumn{7}{|c|}{$\begin{array}{l}\text { Audio Voice over } \\
\end{array}$} \\
\hline 17. & Penggunaan audio voice over terdengar jelas & & & & 10 & 20 \\
\hline
\end{tabular}




\begin{tabular}{|c|c|c|c|c|}
\hline 18. & $\begin{array}{l}\text { Penggunaan voice over di dalam video } \\
\text { membuat anda lebih fokus ketika menonton } \\
\text { film dokumenter }\end{array}$ & 2 & 12 & 16 \\
\hline 19. & $\begin{array}{l}\text { Penggunaan voice over di dalam video } \\
\text { memperjelas dan mempermudah penyampaian } \\
\text { informasi mengenai pariwisata kota batam }\end{array}$ & & 15 & 15 \\
\hline 20. & $\begin{array}{l}\text { Penggunaan voice over di dalam video } \\
\text { membuat informasi mengenai letak wisata lebih } \\
\text { muda di ingat }\end{array}$ & 2 & 14 & 14 \\
\hline 21. & $\begin{array}{l}\text { Penggunaan voice over di dalam video } \\
\text { membuat tambahan informasi baru untuk anda } \\
\text { mengenai pariwisata di kota Batam }\end{array}$ & & 11 & 19 \\
\hline
\end{tabular}

Berikut merupakan tabel merupakan tabel hasil beta testing terhadap responden yang telah diolah.

Tabel 11. Hasil Kuesioner yang telah diolah

\begin{tabular}{|c|c|c|c|}
\hline No. & Pertanyaan & $\begin{array}{l}\text { Total } \\
\text { Skor }\end{array}$ & Interpretensi \\
\hline \multicolumn{4}{|c|}{ Aspek Foley } \\
\hline 1. & $\begin{array}{l}\text { Suara pesawat yang dibuat dengan teknik foley } \\
\text { pada menit 00:02 terdengar seperti suara aslinya }\end{array}$ & 136 & $90.6 \%$ \\
\hline 2. & $\begin{array}{l}\text { Suara langkah kaki yang dibuat dengan teknik } \\
\text { foley pada menit 00:16 terdengar seperti suara } \\
\text { aslinya }\end{array}$ & 133 & $88.6 \%$ \\
\hline 3. & $\begin{array}{l}\text { Suara menginjak botol yang dibuat dengan } \\
\text { teknik foley pada menit 00:19 terdengar seperti } \\
\text { suara aslinya }\end{array}$ & 142 & $94.6 \%$ \\
\hline 4. & $\begin{array}{l}\text { Suara kepakan sayap burung yang dibuat dengan } \\
\text { teknik foley pada menit 00:55 terdengar seperti } \\
\text { suara aslinya }\end{array}$ & 134 & $89.3 \%$ \\
\hline 5. & $\begin{array}{l}\text { Suara ombak yang dibuat dengan teknik foley } \\
\text { pada menit 01:04 terdengar seperti suara aslinya }\end{array}$ & 133 & $88.6 \%$ \\
\hline 6. & $\begin{array}{l}\text { Suara angin yang dibuat dengan teknik foley } \\
\text { pada menit 01:25 terdengar seperti suara aslinya }\end{array}$ & 119 & $79.3 \%$ \\
\hline 7. & $\begin{array}{l}\text { Suara kayuhan sepeda yang dibuat dengan teknik } \\
\text { foley pada menit 01:39 terdengar seperti suara } \\
\text { aslinya }\end{array}$ & 123 & $82 \%$ \\
\hline 8. & $\begin{array}{l}\text { Suara bel sepeda yang dibuat dengan teknik foley } \\
\text { pada menit 01:42 terdengar seperti suara aslinya }\end{array}$ & 139 & $92.6 \%$ \\
\hline 9. & $\begin{array}{l}\text { Suara aktivitas makan yang dibuat dengan teknik } \\
\text { foley pada menit } 02: 10 \text { terdengar seperti suara } \\
\text { aslinya }\end{array}$ & 119 & $79.3 \%$ \\
\hline 10. & $\begin{array}{l}\text { Suara menggoreng makanan yang dibuat dengan } \\
\text { teknik foley pada menit 02:26 terdengar seperti } \\
\text { suara aslinya }\end{array}$ & 130 & $86.6 \%$ \\
\hline 11. & $\begin{array}{l}\text { Suara mengocok telur yang dibuat dengan teknik } \\
\text { foley pada menit 02:28 terdengar seperti suara } \\
\text { aslinya }\end{array}$ & 132 & $88 \%$ \\
\hline 12. & $\begin{array}{l}\text { Suara pintu yang dibuat dengan teknik foley pada } \\
\text { menit 03:04 terdengar seperti suara aslinya }\end{array}$ & 135 & $90 \%$ \\
\hline 13. & $\begin{array}{l}\text { Suara air mengalir yang dibuat dengan teknik } \\
\text { foley pada menit 03:22 terdengar seperti suara } \\
\text { aslinya }\end{array}$ & 133 & $88.6 \%$ \\
\hline 14. & $\begin{array}{l}\text { Penggunaan audio foley pada video membuat } \\
\text { anda ikut merasakan suasana yang terjadi dalam } \\
\text { film dokumenter }\end{array}$ & 136 & $90.6 \%$ \\
\hline 15. & $\begin{array}{l}\text { Penggunaan audio foley pada video membantu } \\
\text { memperjelas keadaan yang terjadi di film } \\
\text { dokumenter }\end{array}$ & 138 & $92 \%$ \\
\hline 16. & $\begin{array}{l}\text { Penggunaan audio foley pada video membuat } \\
\text { perhatian anda lebih terfokus dalam menonton } \\
\text { film dokumenter }\end{array}$ & 134 & $89.3 \%$ \\
\hline \multicolumn{4}{|c|}{ Aspek Voice over } \\
\hline 17. & Penggunaan audio voice over terdengar jelas & 140 & $93.3 \%$ \\
\hline 18. & $\begin{array}{l}\text { Penggunaan voice over di dalam video membuat } \\
\text { anda lebih fokus ketika menonton film } \\
\text { dokumenter }\end{array}$ & 134 & $89.3 \%$ \\
\hline
\end{tabular}




\begin{tabular}{|c|l|c|c|}
\hline 19. & $\begin{array}{l}\text { Penggunaan voice over di dalam video } \\
\text { memperjelas dan mempermudah penyampaian } \\
\text { informasi mengenai pariwisata kota batam }\end{array}$ & 135 & $90 \%$ \\
\hline 20. & $\begin{array}{l}\text { Penggunaan voice over di dalam video membuat } \\
\text { informasi mengenai letak wisata lebih muda di } \\
\text { ingat }\end{array}$ & 132 & $88 \%$ \\
\hline 21. & $\begin{array}{l}\text { Penggunaan voice over di dalam video membuat } \\
\text { tambahan informasi baru untuk anda mengenai } \\
\text { pariwisata di kota Batam }\end{array}$ & $92.6 \%$ \\
\hline
\end{tabular}

Berdasarkan hasil persentase setiap pertanyaan yang telah dijawab oleh responden, maka nilai rata-rata presentasennya dihitung menggunakan rumus :

Jumlah persentase (\%) setiap pertanyaan / Jumlah pertanyaan

Jumlah presentase $=1863.2 / 21$

$=88.7 \%(\mathbf{S S})$

Sesuai dengan interval penilaian skala likert yang sudah ditentukan, maka telah didapatkan nilai dari ahli media dengan 21 pertanyaan dengan hasil persentase penilaian responden yaitu $88.7 \%$. Dan berdasarkan perhitungan skala likert telah Sangat Sesuai (SS) bahwa koresponden setuju dan memahami bahwa implementasi foley dan voice over berpengaruh terhadap film dokumenter Wonderful Batam.

Sehingga hasil dari kuesioner penelitian juga mempertegas teori [1] bahwa dengan adanya suara foley dapat membantu memperjelas suatu keadaan di dalam film secara alami, dan serta voice over juga berguna untuk menyediakan informasi tertentu dan sering menguraikan pesan yang ditujukan kepada audiens agar dapat menangkap informasi secara gamblang [4].

\section{Delivery}

Pada tahapan ini film dokumenter Wonderful Batam yang telah diberikan implementasi teknik foley dan voice over akan didistribusikan secara online menggunakan media sosial seperti youtube dan instagram setelah melakukan penyebaran kuesioner melalui google form untuk melakukan pengujian terlebih dahulu.

\section{KESIMPULAN}

Berdasarkan pengujian dan analisis yang telah dilakukan maka didapata kesimpulan :

1. Implementasi teknik foley dapat memberikan kejelasan suara pada adegan di dalam film dokumenter Wonderful Batam yang ingin diperjelas.

2. Implementasi voice over membantu mempermudah informasi yang ingin disampaikan dari film dokumenter Wonderful batam

3. Dengan membuat film dokumenter Wonderful Batam dan mengimplementasikan foley dan voice over di video tersebut dapat membuat penonton merasakan suasana yang terjadi dalam video dan memperoleh informasi penting dari film dokumenter.

\section{REFERENSI}

[1] T. Holman, Sound for film and television, United Kingdom: Elsevier.Inc, 2010.

[2] H. Wyatt e T. Amyes, Audio Post Production for Television, United Kingdom: Local Press, 2005.

[3] D. Sonnenschein, Sound Design: The Expressive Power of Music, Voice and Sound Effects in Cinema, United States of America: Michael Wise Production, 2001.

[4] T. Waiwai, Dunia Voice Over, Jakarta: W Publishing, 2018.

[5] I. Binanto, "Perbandingan Metode Pengembangan Perangkat Lunak," Prosiding Seminar RiTekTra, Yogyakarta, 2013.

[6] E. M. Lawrent, "Implementasi Teknik Foley Pada Film Pendek Aanimasi 2D Stop Kekerasan Pada Anak," Politeknik Negeri Batam, Batam, 2019. 
[7] E. S. Kriswanto e Komari, Pengembangan Company Profile Prodi PJKR Jurusan POR FIK UNY Berbasis Audio Visual, Yogyakarta, 2014.

[8] W. Budiaji, "Skala pengukuran dan jumlah respon," Jurnal Ilmu Pertanian dan Perikanan, pp. 126133, 2013.

[9] R. Likert, Technique for the measurement of attitudes, Archives of psychology, 1932.

[10] . A. De Götzen, "Real, foley or synthetic? An evaluation of everyday walking sounds," Proceedings of SMC 2013.

[11] R. Vier, The Sound Effects Bible: How to Create and Record Hollywood Style Sound Effects, California, United States.: Michael Wiese Productions, 2008.

[12] Suryani, S; Hendriyadi,H, Metode Riset Kuantitatif: Teori dan Aplikasi Pada Penelitian Bidang Manajemen dan Ekonomi Islam., Jakarta: Prenada Media Group, 2016.

[13] S. Trento e A. De gotzen, Foley sounds vs. real sounds, Padova: Proceedings of the Sound and Music Computing Conference, 2011. 